Archive for

Organic Chemistry

Arkivoc 2020, part viii, 1-11

\title{
Synthesis of fluorosolvatochromic phenanthrenyl-substituted benzoquinolizinium derivatives
}

\author{
Phil M. Pithan, Katja Schwan, and Heiko Ihmels* \\ Department of Chemistry and Biology, University of Siegen, and Center of Micro- and Nanochemistry and \\ Engineering ( $\mathrm{C} \mu$ ); Adolf-Reichwein-Str. 2, 57068 Siegen, Germany \\ Email:ihmels@chemie.uni-siegen.de
}

Received 07-13-2020

Accepted 08-22-2020

Published on line $09-28-2020$

\section{Abstract}

The biaryl derivatives 8-(phenanthren-9-yl)benzo[c]quinolizinium and 9-(phenanthren-9-yl)benzo[b]quinolizinium were synthesized by a Suzuki-Miyaura coupling, and their steady-state absorption and emission properties were investigated. Whereas the absorption properties are essentially independent of the solvent properties, these compounds show a pronounced fluorosolvatochromism. Namely, they exhibit their lowestenergy maximum in aprotic, polar solvents and significantly blue-shifted emission bands in polar protic solvents. Notably, comparison of three different phenanthrenyl-substituted quinolizinium derivatives revealed that these fluorosolvatochromic properties are essentially independent of the annelation pattern of the quinolizinium unit, given that the aryl substituent has the propensity to form a sufficiently stabilized radical cation upon a photoinduced charge shift in the biaryl derivative.<smiles>Brc1ccc2c[n+]3cccc-3ccc2c1</smiles>

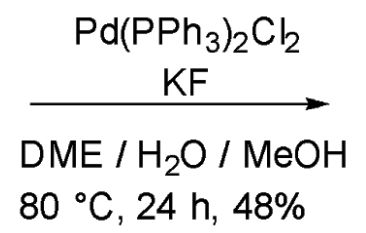<smiles>c1ccc2c(c1)cc(-c1ccc3cccc[n+]3c1)c1ccccc12</smiles>

Keywords: Quinolizinium, heterocycles, fluorescence, solvatochromism 


\section{Introduction}

Cationic heteroaromatic compounds are useful components for the construction and development of functional dyes. ${ }^{1-6}$ Because of their intrinsic electron-accepting properties they are easily integrated into donor-acceptor systems with favorable optical properties, such as red-shifted absorption and emission bands, large extinction coefficients, and high emission quantum yields, that are essential prerequisites for application as molecular fluorescent probes. ${ }^{7,8}$ In particular, the emission properties of these compounds are often highly sensitive to the surrounding medium so that they can be employed as solvatochromic probes in fluorescence sensing and imaging. ${ }^{9}$ In this context, we and others have established benzo-annelated quinolizinium ions as versatile units in water-soluble fluorescent probes, ${ }^{10}$ for example for the fluorimetric detection of $\mathrm{pH}, \mathrm{metal}$ cations, or

DNA. ${ }^{11-19}$ In addition, we have demonstrated that biaryl-type quinolizinium derivatives $\mathbf{1 a - d}$ and $\mathbf{2 a - c}$ (Figure 1), that carry either a donor-substituted phenyl substituent or an electron-rich polycyclic aryl substituent, exhibit a pronounced fluorosolvatochromic behavior, i.e., they cover a large range of emission maxima in different solvents. ${ }^{20,21}$ Specifically, the emission energy of these compounds depends on the polarity and hydrogen-bonding properties of the employed solvents because these parameters contribute significantly to the stabilization or destabilization of the intermediates that are formed after a photoinduced charge shift in the excited state. Thus, the biaryl-type quinolizinium fluorophore may be considered as promising structural motif of novel solvatochromic probes with solvent-sensitive emission properties that deserves further investigation to assess its scope and limits. As we have shown that the structural features of the polycyclic aromatic substituents in $\mathbf{2 a - c}$ have a significant influence on the solvatochromic properties, we were additionally interested in the effect of the size and shape of the annelated quinolizinium ion. For that purpose, we focussed our attention on biaryl derivatives with a benzo-annelated quinolizinium unit to test whether the interplay of the smaller benzoquinolizinium with the phenanthrenyl substituent in the excited state still leads to fluorosolvatochromic behavior. The phenanthrenyl benzoquinolizinium $\pi$-system, the angular derivative $\mathbf{5}$ and the linearly annelated isomer $\mathbf{8}$ were designated as target structures. Herein, we present the synthesis of these derivatives, along with an investigation of their absorption and emission properties.

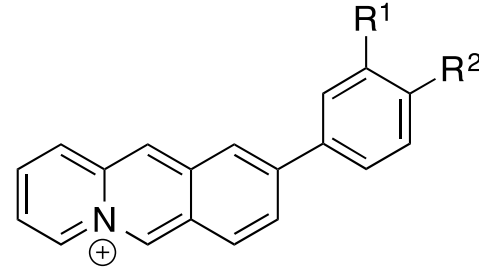

1a: $R^{1}=\mathrm{OMe} ; \mathrm{R}^{2}=\mathrm{H}$

1b: $R^{1}=H ; R^{2}=O M e$

1c: $\mathrm{R}^{1}=\mathrm{OMe} ; \mathrm{R}^{2}=\mathrm{OMe}$

1d: $\mathrm{R}^{1}-\mathrm{R}^{2}=-\mathrm{O}\left(\mathrm{CH}_{2} \mathrm{CH}_{2} \mathrm{O}\right)_{4}$

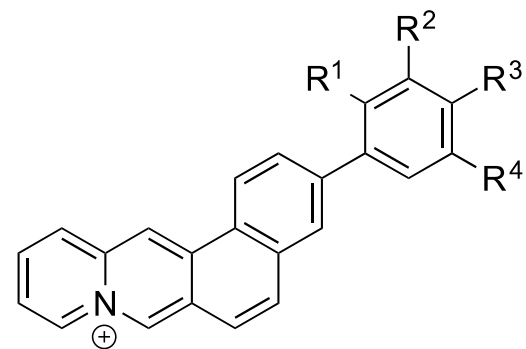

2a: $R^{1}=R^{2}=H, R^{3}=R^{4}=$

2b: $R^{3}=R^{4}=H, R^{1}=R^{2}=$

2c: $R^{1}=R^{2}=$ ?

Figure 1. Structures of biaryl-type quinolizinium derivatives $\mathbf{1 a - d}$ and $\mathbf{2 a - c}$. 


\section{Results and Discussion}

\section{Synthesis}

As Pd-mediated coupling reactions are known to be efficient routes to cationic biaryl derivatives, ${ }^{22-25}$ the product 5 should be synthesizable by the reaction of the known phenanthrene-9-boronic acid (4) and the 8bromobenzo[c]quinolizinium 3c. However, much to our surprise, the latter compound was not known so far, so that a synthetic route to this substrate had to be explored, first. According to a literature procedure, ${ }^{26}$ the nitrobenzo[c]quinolizinium $3 a^{27,28}$ was reduced with activated iron to the corresponding amino-substituted compound $\mathbf{3 b}$ that was isolated as its tetrafluoroborate salt by ion metathesis in $62 \%$ yield (Scheme 1).

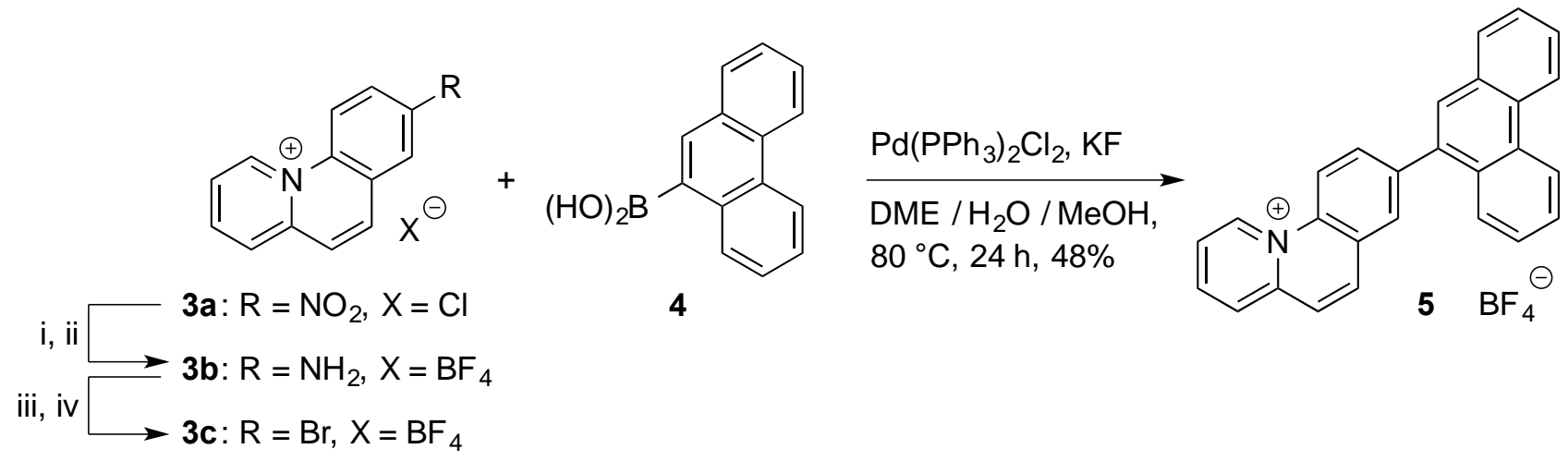

Scheme 1. Synthesis of 8-(phenanthren-9-yl)benzo[c]quinolizinium tetrafluoroborate (5). Reagents and reaction conditions: i) Fe, aq. $\mathrm{HCl}(37 \%)$, aq. $\mathrm{NH}_{4} \mathrm{Cl}(25 \%), \mathrm{EtOH}, 65^{\circ} \mathrm{C}, 2 \mathrm{~h}$; ii) $\mathrm{NaBF}_{4}, \mathrm{H}_{2} \mathrm{O}, 62 \%$; iii) $\mathrm{NaNO}_{2}$, aq. $\mathrm{HBr}(24 \%), 0^{\circ} \mathrm{C}, 10 \mathrm{~min}$; iv) $\mathrm{CuBr}$, aq. $\mathrm{HBr}(48 \%), \mathrm{rt}, 1 \mathrm{~h}, 26 \%$.

The use of iron as the reducing agent turned out to be superior to the previously employed method with $\mathrm{SnCl}_{2}$ that gave $\mathbf{3 b}$ only in low yields. ${ }^{27}$ The amine $3 \mathbf{b}$ was diazotized with $\mathrm{NaNO}_{2}$ in hydrobromic acid and subsequently converted into 8-bromobenzo[c]quinolizinium (3c) in a Sandmeyer reaction by the use of $\mathrm{CuBr}$. The intermediate diazonium salt was prone to decomposition under the reaction conditions due to the electron-poor aromatic system resulting only in a moderate yield of $26 \%$ for the latter reaction step. According to established protocol, ${ }^{25}$ the Suzuki-Miyaura coupling of the benzo[c]quinolizinium $3 c$ with phenanthrene-9boronic acid (4) with $\mathrm{Pd}\left(\mathrm{PPh}_{3}\right)_{2} \mathrm{Cl}_{2}$ as catalyst and $\mathrm{KF}$ as weak base gave the biaryl product 5 in $48 \%$ yield. The linearly annelated derivative $\mathbf{8}$ was also available by a Suzuki-Miyaura coupling reaction. In this case, the Pdmediated reaction of the known benzo[b]quinolizinium-9-boronic acid (6) ${ }^{25}$ and 9-bromophenanthrene (7) furnished the 9-phenanthrenyl-substituted benzo[b]quinolizinium (8) in 16\% yield (Scheme 2). The structures of the new compounds 3c, 5, and 8 were confirmed by NMR spectroscopy $\left({ }^{1} \mathrm{H},{ }^{13} \mathrm{C}, \operatorname{COSY}, \mathrm{HSQC}, \mathrm{HMBC}\right)$, elemental analysis, and electrospray ionization mass spectrometric analysis (ESI-MS). 


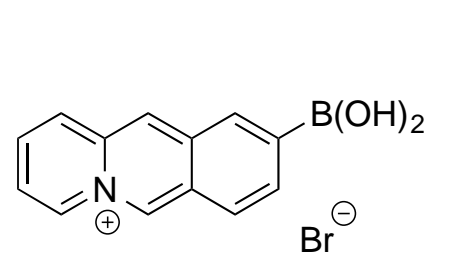

6

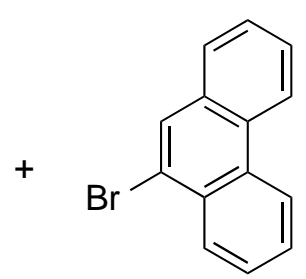

7

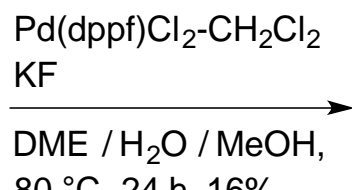

$80{ }^{\circ} \mathrm{C}, 24 \mathrm{~h}, 16 \%$

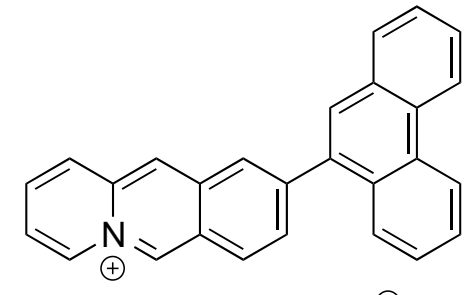

$8 \mathrm{Br}^{\ominus}$

Scheme 2. Synthesis of 9-(phenanthren-9-yl)benzo[b]quinolizinium bromide (8), dppf = 1,1'bis(diphenylphosphino)ferrocene.

\section{Photophysical properties}

The biaryl $\mathbf{5}$ is soluble in polar protic and polar aprotic solvents and exhibits the characteristic, albeit slightly red-shifted long-wavelength absorption band of the parent benzo[c]quinolizinium with two local maxima between 350 and $370 \mathrm{~nm} .^{27}$ The shift of the absorption maximum of this compound ranges from $368 \mathrm{~nm}$ in $\mathrm{H}_{2} \mathrm{O}\left(\varepsilon=12000 \mathrm{M}^{-1} \mathrm{~cm}^{-1}\right)$ to $371 \mathrm{~nm}$ in DMSO $\left(\varepsilon=17300 \mathrm{M}^{-1} \mathrm{~cm}^{-1}\right)$ and is thus essentially independent of the solvent (Figure $2 \mathrm{~A}$, Table 1). In contrast, the maxima of the broad emission bands vary from $544 \mathrm{~nm}$ to $581 \mathrm{~nm}$ in those solvents (Figure $2 \mathrm{~B}$, Figure 3, Table 1). At the same time, the highest fluorescence quantum yield was observed in $1-\mathrm{BuOH}\left(\Phi_{\mathrm{fl}}=0.14\right)$ and the lowest one in $\mathrm{H}_{2} \mathrm{O}\left(\Phi_{\mathrm{fl}}=0.012\right)$. Unfortunately, the absorption and emission properties of 5 in other, non-polar solvents (e.g., $\mathrm{CH}_{2} \mathrm{Cl}_{2}$ and $\mathrm{CHCl}_{3}$ ) could not be determined due to very low solubility. Although the investigations of the absorption and emission properties of the linearly annelated quinolizinium derivative $\mathbf{8}$ were somewhat hampered by its low solubility in organic solvents and water, the data obtained in representative solvents revealed a similar trend as with the angular isomer 5 (Table 1, Figure 4). Specifically, the absorption properties do not change significantly in different solvents and range from $397 \mathrm{~nm}$ in $\mathrm{H}_{2} \mathrm{O}$ and $\mathrm{MeCN}$ to $402 \mathrm{~nm}$ in $\mathrm{CHCl}_{3}$ (Figure 4A). In contrast, this compound has a pronounced fluorosolvatochromic behavior as indicated by a shift of the emission maximum from 500 $\mathrm{nm}$ in $\mathrm{CHCl}_{3}$ to

$557 \mathrm{~nm}$ and $558 \mathrm{~nm}$ in DMSO and MeCN, respectively (Figure 4B). It should be noted that compound 8 does not dissolve well in water and may tend to aggregation at higher concentrations in this solvent, as indicated by the absorption spectrum; however, the solubility is suffient at the low concentrations employed for fluorescence measurements.
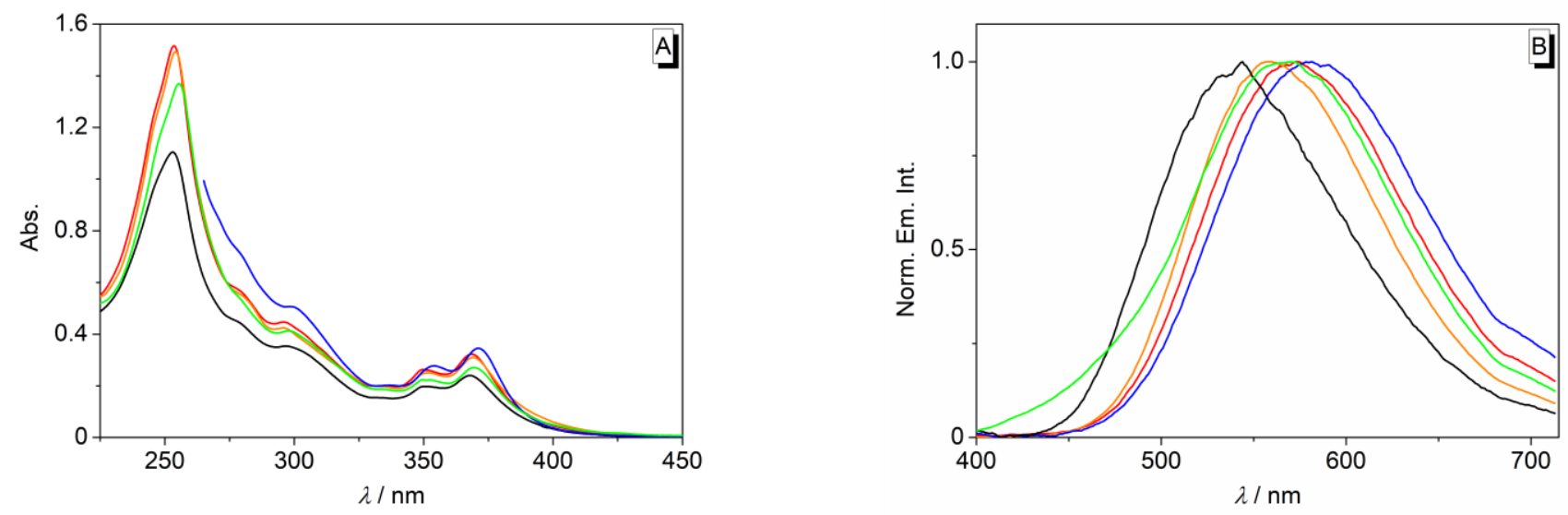

Figure 2. Absorption $(c=20 \mu \mathrm{M})(\mathrm{A})$ and normalized emission spectra (Abs. $=0.10$ at $\left.\lambda_{\mathrm{ex}}=365 \mathrm{~nm}\right)(\mathrm{B})$ of derivative 5 in $\mathrm{H}_{2} \mathrm{O}$ (black), $\mathrm{MeOH}$ (red), 2-PrOH (orange), THF (green), and DMSO (blue). 
Table 1. Absorption and emission properties of derivatives 5 and 8

\begin{tabular}{|c|c|c|c|c|c|c|c|c|}
\hline \multirow[b]{2}{*}{ Solvent $^{a}$} & \multicolumn{4}{|c|}{5} & \multicolumn{4}{|c|}{8} \\
\hline & $\lambda_{\mathrm{abs}}^{b}$ & $\lg \varepsilon^{c}$ & $\lambda_{\mathrm{fl}}{ }^{d}$ & $\Phi_{\mathrm{fl}}^{e} / 10^{-2}$ & $\lambda_{\mathrm{abs}}^{b}$ & $\lg \varepsilon^{c}$ & $\lambda_{\mathrm{fl}}{ }^{g}$ & $\Phi_{\mathrm{fl}}^{e} / 10^{-2}$ \\
\hline $\mathrm{H}_{2} \mathrm{O}$ & 368 & 4.08 & 544 & 1.2 & 397 & 3.62 & 532 & 5.6 \\
\hline $\mathrm{MeOH}$ & 369 & 4.21 & 573 & 3.9 & 398 & 4.06 & 553 & 15 \\
\hline $\mathrm{EtOH}$ & 369 & 4.18 & 563 & 9.0 & $-^{h}$ & $-^{h}$ & $--^{h}$ & $-{ }^{h}$ \\
\hline $\mathrm{AcOH}$ & 369 & 4.18 & 562 & 8.1 & $--^{h}$ & $--^{h}$ & $-{ }^{h}$ & $-{ }^{h}$ \\
\hline 1-BuOH & 370 & 4.19 & 564 & 14 & $--^{h}$ & $-{ }^{h}$ & $-{ }^{h}$ & $--^{h}$ \\
\hline 2-PrOH & 369 & 4.19 & 558 & 13 & $f$ & $f^{f}$ & $f^{f}$ & $f^{f}$ \\
\hline $\mathrm{MeCN}$ & 368 & 4.19 & 581 & 6.4 & 397 & 4.06 & 558 & 14 \\
\hline DMSO & 371 & 4.24 & 581 & 4.8 & 399 & 4.00 & 557 & 15 \\
\hline $\mathrm{CHCl}_{3}$ & $-^{f}$ & $f^{f}$ & $-f$ & ${ }^{f}$ & 402 & 4.02 & 500 & 5.9 \\
\hline THF & 369 & 4.13 & 570 & 8.4 & 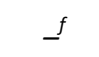 & ${ }^{f}$ & $f^{f}$ & ${ }^{f}$ \\
\hline
\end{tabular}

${ }^{a}$ Solvents arranged in order of decreasing $E_{\mathrm{T}}{ }^{30}$ values. ${ }^{b}$ Long-wavelength absorption maximum in $\mathrm{nm} ; c=$ $20 \mu \mathrm{M}$. ${ }^{c}$ Molar extinction coefficient in $\mathrm{cm}^{-1} \mathrm{M}^{-1}$. ${ }^{d}$ Fluorescence emission maximum (Abs $=0.10$ at excitation wavelength $\left.\lambda_{\mathrm{ex}}=365 \mathrm{~nm}\right) .{ }^{e}$ Fluorescence quantum yield relative to Coumarin $153\left(\Phi_{\mathrm{fl}}=0.38\right.$ in EtOH) [Ref. 3032]; estimated error for fluorescence quantum yields: $\pm 10 \% .{ }^{f}$ Not sufficiently soluble. ${ }^{g}$ Fluorescence emission maximum (Abs. $=0.10$ at excitation wavelength $\lambda_{\mathrm{ex}}=399 \mathrm{~nm}$ ). ${ }^{h}$ Not determined.

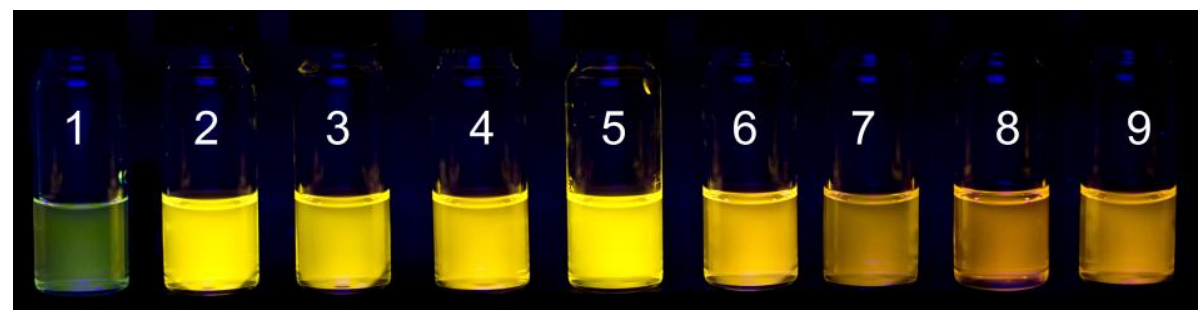

Figure 3. Emission colors of derivative 5 in various solvents; $\lambda_{\mathrm{ex}}=366 \mathrm{~nm} .1: \mathrm{H}_{2} \mathrm{O}, 2: 2-\mathrm{PrOH}, 3: \mathrm{AcOH}, 4: \mathrm{EtOH}$, 5: 1-BuOH, 6: THF, 7: MeOH, 8: MeCN, 9: DMSO. 

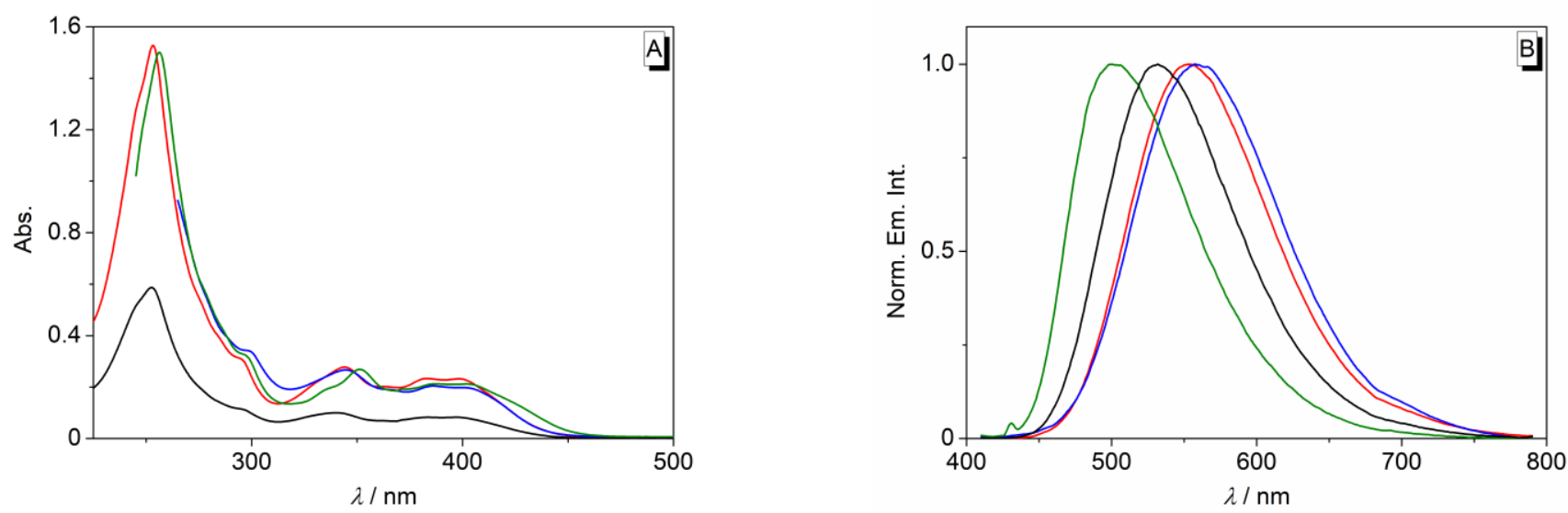

Figure 4. Absorption $(c=20 \mu \mathrm{M})(\mathrm{A})$ and normalized emission spectra (Abs. $=0.10$ at $\left.\lambda_{\mathrm{ex}}=399 \mathrm{~nm}\right)(\mathrm{B})$ of derivative 8 in $\mathrm{H}_{2} \mathrm{O}$ (black), $\mathrm{MeOH}$ (red), $\mathrm{CHCl}_{3}$ (olive), and DMSO (blue).

Altogether, all three phenanthrenyl-substituted, annelated quinolizinium derivatives $\mathbf{2 c}$, $\mathbf{5}$, and $\mathbf{8}$ possess similar solvatochromic properties. Namely, they exhibit their lowest-energy maximum in the polar aprotic solvents MeCN and DMSO and a blue-shifted emission band in polar protic solvents, mostly pronounced in water. Moreover, in the case of derivatives $2 \mathrm{c}$ and $\mathbf{8}$ the strongest blue shift was observed in $\mathrm{CHCl}_{3}$ solution, whereas $\mathbf{5}$ is not sufficiently soluble in this solvent. The origin of this solvatochromism has been discussed previously, and it was proposed that it is mainly caused and influenced by the polarity and the hydrogenbonding properties of the solvents. ${ }^{20}$ According to this model, a photoinduced charge shift (CS) leads to the formation of a quinolizinyl intermediate, e.g. $\mathbf{8}^{\mathrm{CS}}$, that is connected with the phenanthrene radical cation (Scheme 3). In turn, the specific energetic stabilization of the excited CS state by the various solvents leads to varying emission energies. Nevertheless, as already observed with derivative 2c, the emission maxima do correlate reasonably well with the established solvent parameters, that quantify, for example, the polarity, polarizability, or the hydrogen bond donating and accepting properties, which clearly indicates that the different solvent parameters affect the emission properties to different extents and with different trends. Unfortunately, the low solubility of the substrates in most organic solvents hampers a multiparameter analysis of the solvent effect. In summary, we deduce from the comparison of the fluorosolvatochromic properties of derivatives $\mathbf{2 c}, \mathbf{5}$, and $\mathbf{8}$ that in all cases the CS state is formed on photoexcitation and that the interaction with the surrounding medium of the corresponding intermediate after solvent relaxation is specific for each solvent. And although this a rather small sample size, so far, the results seem to indicate that the fluorosolvatochromic properties of biaryl-type quinolizinium ions are essentially independent of the size and shape of the annelated quinolizinium fluorophore.

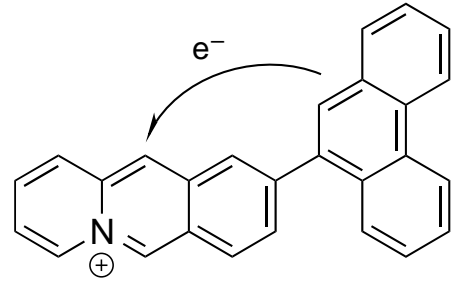

8

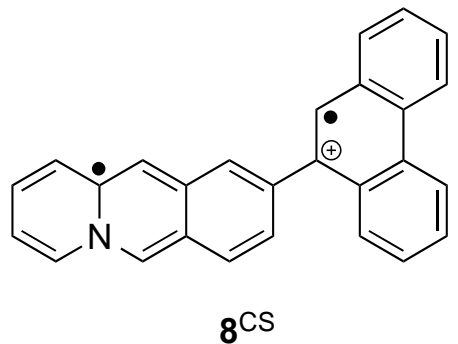

$8^{\mathrm{CS}}$

Scheme 3. Intramolecular charge shift of benzoquinolizinium ion 8 upon photoexcitation. 


\section{Conclusions}

In summary, Suzuki-Miyaura coupling was employed as key step for the synthesis of two novel phenanthrenylsubstituted benzoquinolizinium derivatives $\mathbf{5}$ and $\mathbf{8}$, whose emission properties depend strongly on the solvent. Notably, comparison of three different phenanthrenyl-substituted quinolizinium derivatives revealed that the pronounced fluorosolvatochromic properties are essentially independent of the annelation pattern of the quinolizinium unit. Therefore, it may be concluded that an annelated quinolizinium fluorophore with a biaryl structure is generally fluorosolvatochromic as long as the aryl substituent has the propensity to form a stabilized radical cation upon a photoinduced charge shift. This observation emphasizes the utility of the quinolizinium ion as a key element in fluorescent probes ${ }^{10}$ and should be relevant for the development of functional solvatochromic probes, because the size and shape of the annelated quinolizinium unit may be simply adapted to a particular application without loss of fluorosolvatochromic properties.

\section{Experimental Section}

General. 8-Nitrobenzo[c]quinolizinium chloride (3a) was prepared from 2-chloro-5-nitrobenzaldehyde and 2methylpyridine as previously described. ${ }^{27,28}$ Phenanthrene-9-boronic acid (4) was synthesized from 9-bromophenanthrene (7) according to a literature procedure. ${ }^{29}$ Benzo[b]quinolizinium-9-boronic acid (6) was synthesized as previously described. ${ }^{25}$ 9-Bromophenanthrene (7) was purchased from Merck KGaA (Darmstadt, D). The commercially available chemicals were reagent-grade and used without further purification. Absorption and emission spectra were recorded from solutions prepared with spectroscopic grade solvents.

For experiments in different solvents, aliquots of the stock solution of $\mathbf{5}(c=1.0 \mathrm{mM}$ in MeCN) or $\mathbf{8}(c=1.0 \mathrm{mM}$ in $\mathrm{MeOH}$ ) were evaporated under a stream of nitrogen and redissolved in the respective solvent. In general, absorption spectra were determined in a range between $225 \mathrm{~nm}$ and $500 \mathrm{~nm}$ (265-500 nm for DMSO and $\mathrm{AcOH}, 245-500 \mathrm{~nm}$ for $\mathrm{CHCl}_{3}$ ) and subsequently smoothed in the Origin software with the function "adjacentaveraging" (factor of 10). For the detection of emission spectra, the excitation and emission slits were adjusted to $5 \mathrm{~nm}$, the detection speed was $120 \mathrm{~nm} \mathrm{~min}^{-1}$, and the detector voltage was adjusted to $600 \mathrm{~V}$. The emission spectra were smoothed with the implemented moving-average function by a factor of 5 , but they are otherwise uncorrected despite a potentially reduced detector sensitivity above $600 \mathrm{~nm}$. The fluorescence quantum yields of derivative $\mathbf{5}$ and $\mathbf{8}$ were determined relative to Coumarin $153\left(\Phi_{\mathrm{fl}}=0.38 \text { in EtOH }\right)^{30}$ according to the established procedures. ${ }^{31,32}$

8-Aminobenzo[c]quinolizinium tetrafluoroborate (3b). A suspension of iron powder $(1.40 \mathrm{~g}, 25.0 \mathrm{mmol})$ in EtOH $(8 \mathrm{~mL})$ and aq. $\mathrm{HCl}$ solution $(w=37 \%, 208 \mu \mathrm{L})$ was stirred at $65^{\circ} \mathrm{C}$ for $2 \mathrm{~h}$, after which an aq. $\mathrm{NH}_{4} \mathrm{Cl}$ solution ( $w=25 \%, 4 \mathrm{~mL}$ ) was added. Then, the nitroquinolizinium $3 \mathrm{a}(1.30 \mathrm{~g}, 5.00 \mathrm{mmol})$ was added in portions over a period of $30 \mathrm{~min}$. The reaction mixture was stirred at $60^{\circ} \mathrm{C}$ for $2 \mathrm{~h}$, cooled to $40^{\circ} \mathrm{C}$, and filtered through a pad of $\mathrm{SiO}_{2}(10 \mathrm{~g})$. The latter was washed with $\mathrm{EtOH}(350 \mathrm{~mL})$, and the solvent was removed under reduced pressure. The residue was dissolved in $\mathrm{H}_{2} \mathrm{O}(20 \mathrm{~mL})$ and a sat. solution of $\mathrm{NaBF}_{4}(3.29 \mathrm{~g}, 30.0 \mathrm{mmol})$ in $\mathrm{H}_{2} \mathrm{O}$ was added. After cooling to $0{ }^{\circ} \mathrm{C}$, the precipitate was filtered off and washed with cold $\mathrm{H}_{2} \mathrm{O}(5 \mathrm{~mL})$ and $\mathrm{MeOH}(5 \mathrm{~mL})$. The product $\mathbf{3 b}$ was crystallized from $\mathrm{MeOH} / \mathrm{H}_{2} \mathrm{O}(1: 1,8 \mathrm{~mL})$, dried in a vacuum desiccator over $\mathrm{CaCl}_{2}$ and obtained in the form of fine, brown needles $(878 \mathrm{mg}, 3.11 \mathrm{mmol}, 62 \%) ; \mathrm{mp} 238-240{ }^{\circ} \mathrm{C}$ (dec.) (lit. ${ }^{27}$ mp 228-229 $\left.{ }^{\circ} \mathrm{C}\right) .{ }^{1} \mathrm{H}-\mathrm{NMR}\left(400 \mathrm{MHz}, \mathrm{DMSO}-\mathrm{d}_{6}\right): \delta=6.42\left(\mathrm{~s}, 2 \mathrm{H}, 8-\mathrm{NH}_{2}\right), 7.13\left(\mathrm{~d},{ }^{4} \mathrm{~J} 2 \mathrm{~Hz}, 1 \mathrm{H}, 7-\mathrm{H}\right), 7.38$ (dd, ${ }^{3}$ J 
$\left.9 \mathrm{~Hz},{ }^{4} \mathrm{~J} 2 \mathrm{~Hz}, 1 \mathrm{H}, 9-\mathrm{H}\right), 8.07-8.14(\mathrm{~m}, 2 \mathrm{H}, 2-\mathrm{H}, 5-\mathrm{H}), 8.35-8.42(\mathrm{~m}, 2 \mathrm{H}, 3-\mathrm{H}, 6-\mathrm{H}), 8.49\left(\mathrm{~d},{ }^{3} \mathrm{~J} 8 \mathrm{~Hz}, 1 \mathrm{H}, 4-\mathrm{H}\right)$, $8.78\left(\mathrm{~d},{ }^{3} \mathrm{~J} 9 \mathrm{~Hz}, 1 \mathrm{H}, 10-\mathrm{H}\right), 10.04\left(\mathrm{~d},{ }^{3} \mathrm{~J} 7 \mathrm{~Hz}, 1 \mathrm{H}, 1-\mathrm{H}\right)$. Anal. for $\mathrm{C}_{13} \mathrm{H}_{11} \mathrm{BF}_{4} \mathrm{~N}_{2}$ (282.05), calcd (\%): C 55.36, H 3.93, N 9.93, found: C 55.36, H 3.94, N 9.80.

8-Bromobenzo[c]quinolizinium tetrafluoroborate (3c). To prepare the $\mathrm{CuBr}$ catalyst solution, first $\mathrm{NaBr}$ (309 mg, $3.00 \mathrm{mmol}$ ) was added to a solution of $\mathrm{CuSO}_{4} .7 \mathrm{H}_{2} \mathrm{O}(499 \mathrm{mg}, 2.00 \mathrm{mmol})$ in $\mathrm{H}_{2} \mathrm{O}(1.60 \mathrm{~mL})$ at $60{ }^{\circ} \mathrm{C}$. Then, a solution of $\mathrm{Na}_{2} \mathrm{SO}_{3}(126 \mathrm{mg}, 1.00 \mathrm{mmol})$ in $\mathrm{H}_{2} \mathrm{O}(400 \mu \mathrm{L})$ was added dropwise. After cooling to rt, the precipitated white $\mathrm{CuBr}$ was washed with $\mathrm{H}_{2} \mathrm{O}(3 \times 5 \mathrm{~mL})$ and dissolved in aq. $\mathrm{HBr}$ solution $(w=48 \%, 800 \mu \mathrm{L})$.

To a solution of the amine $3 b(423 \mathrm{mg}, 1.50 \mathrm{mmol})$ in aq. $\mathrm{HBr}$ solution $(w=24 \%, 1.50 \mathrm{~mL})$ was added a solution of $\mathrm{NaNO}_{2}(109 \mathrm{mg}, 1.58 \mathrm{mmol})$ in $\mathrm{H}_{2} \mathrm{O}(630 \mu \mathrm{L})$ while stirring vigorously at $0{ }^{\circ} \mathrm{C}$. The reaction mixture was stirred at $0{ }^{\circ} \mathrm{C}$ for $10 \mathrm{~min}$ and then added to the $\mathrm{CuBr}$ catalyst solution. The resulting suspension was stirred at rt for $1 \mathrm{~h}$, after which $\mathrm{H}_{2} \mathrm{O}(40 \mathrm{~mL})$ was added and the mixture was filtered from insoluble components. The filtrate was mixed with a sat. solution of $\mathrm{NaBF}_{4}(1.65 \mathrm{~g}, 15.0 \mathrm{mmol})$ in $\mathrm{H}_{2} \mathrm{O}$ and extracted with $\mathrm{MeNO}_{2}(2 \times 25 \mathrm{~mL})$. The combined organic layers were washed with $\mathrm{H}_{2} \mathrm{O}(2 \times 20 \mathrm{~mL})$, dried with $\mathrm{Na}_{2} \mathrm{SO}_{4}$ and filtered from the drying agent. The solvent was removed under reduced pressure. The product $3 c$ was crystallized from $\mathrm{MeCN} / \mathrm{H}_{2} \mathrm{O}$, dried in a vacuum desiccator over $\mathrm{CaCl}_{2}$, and obtained as a brown, microcrystalline solid $(134 \mathrm{mg}, 387 \mu \mathrm{mol}, 26 \%) ; \mathrm{mp} 235-237{ }^{\circ} \mathrm{C}$ (dec.). $-{ }^{1} \mathrm{H}-\mathrm{NMR}\left(600 \mathrm{MHz}, \mathrm{DMSO}-d_{6}\right): \delta=$ 8.29 (ddd, $\left.{ }^{3} \mathrm{~J} 7 \mathrm{~Hz},{ }^{3} \mathrm{~J} 7 \mathrm{~Hz},{ }^{4} \mathrm{~J} 2 \mathrm{~Hz}, 1 \mathrm{H}, 2-\mathrm{H}\right), 8.37$ (dd, ${ }^{3} \mathrm{~J} 9 \mathrm{~Hz},{ }^{4}$ J $\left.2 \mathrm{~Hz}, 1 \mathrm{H}, 9-\mathrm{H}\right), 8.42\left(\mathrm{~d},{ }^{3}\right.$ J $\left.9 \mathrm{~Hz}, 1 \mathrm{H}, 5-\mathrm{H}\right), 8.64$ (d, $\left.{ }^{3} \mathrm{~J} 9 \mathrm{~Hz}, 1 \mathrm{H}, 6-\mathrm{H}\right), 8.67-8.72(\mathrm{~m}, 3 \mathrm{H}, 3-\mathrm{H}, 4-\mathrm{H}, 7-\mathrm{H}), 9.09$ (d, $\left.{ }^{3} \mathrm{~J} 9 \mathrm{~Hz}, 1 \mathrm{H}, 10-\mathrm{H}\right), 10.38\left(\mathrm{~d},{ }^{3} \mathrm{~J} 7 \mathrm{~Hz}, 1 \mathrm{H}, 1-\mathrm{H}\right) .-$ ${ }^{13} \mathrm{C}-\mathrm{NMR}\left(150 \mathrm{MHz}, \mathrm{DMSO}-d_{6}\right): \delta=120.4$ (C10), 123.5 (C8), 124.1 (C5), 124.5 (C2), 128.3 (C6a), 128.5 (C4), 132.2 (C7), 133.4 (C10a), 134.8 (C1), 135.1 (C9), 135.2 (C6), 141.0 (C3), 143.1 (C4a). - MS (ESI $\left.{ }^{+}\right): \mathrm{m} / z=258$ (100) $\left[\mathrm{M}-\mathrm{BF}_{4}\right]^{+} .-\mathrm{MS}\left(\mathrm{ESI}^{-}\right): \mathrm{m} / z=779(100)\left[2 \mathrm{M}+\mathrm{BF}_{4}\right]^{-}$. Anal. for $\mathrm{C}_{13} \mathrm{H}_{9} \mathrm{BBrF}_{4} \mathrm{~N}$ (345.93), calcd (\%): C 45.14, H 2.62, N 4.05, found: C 45.54, H 2.61, N 4.76.

8-(Phenanthren-9-yl)benzo[c]quinolizinium tetrafluoroborate (5). Under an argon atmosphere, a suspension of the bromo-substituted quinolizinium 3c $(120 \mathrm{mg}, 350 \mu \mathrm{mol})$, phenanthrene-9-boronic acid $(4,81.6 \mathrm{mg}$, $368 \mu \mathrm{mol}), \mathrm{KF}(81.3 \mathrm{mg}, 1.40 \mathrm{mmol})$ and $\mathrm{Pd}\left(\mathrm{PPh}_{3}\right)_{2} \mathrm{Cl}_{2}(7.37 \mathrm{mg}, 10.5 \mu \mathrm{mol})$ in $\mathrm{DME} / \mathrm{MeOH} / \mathrm{H}_{2} \mathrm{O}(2 / 1 / 1,4.2 \mathrm{~mL})$ was stirred for $24 \mathrm{~h}$ at $80^{\circ} \mathrm{C}$. After cooling to $\mathrm{rt}$, MeCN $(40 \mathrm{~mL})$ was added, and the reaction mixture was filtered from insoluble components. The solvents were removed under reduced pressure, and the residue was dissolved in $\mathrm{MeNO}_{2}(50 \mathrm{~mL})$. The organic layer was washed with $\mathrm{H}_{2} \mathrm{O}(3 \times 20 \mathrm{~mL})$, dried with $\mathrm{Na}_{2} \mathrm{SO}_{4}$ and filtered from the drying agent. The solvent was removed under reduced pressure. The residue was dissolved in DMSO $(4 \mathrm{~mL})$ and added dropwise to EtOAc $(100 \mathrm{~mL})$ under vigorous stirring. The precipitate was filtered off, washed with EtOAc and $\mathrm{Et}_{2} \mathrm{O}(20 \mathrm{~mL}$ each) and dried in vacuo. The product 5 was obtained as beige, amorphous solid (74.0 mg, $167 \mu \mathrm{mol}, 48 \%)$; $\mathrm{mp} \mathrm{286-290}{ }^{\circ} \mathrm{C}$ (dec.). $-{ }^{1} \mathrm{H}-\mathrm{NMR}\left(600 \mathrm{MHz}, \mathrm{DMSO}-d_{6}\right): \delta=7.64-$ $7.67\left(\mathrm{~m}, 1 \mathrm{H}, 7^{\prime}-\mathrm{H}\right), 7.69-7.72\left(\mathrm{~m}, 1 \mathrm{H}, 2^{\prime}-\mathrm{H}\right), 7.74-7.78\left(\mathrm{~m}, 2 \mathrm{H}, 3^{\prime}-\mathrm{H}, 6^{\prime}-\mathrm{H}\right), 7.81\left(\mathrm{~d},{ }^{3} \mathrm{~J} 8 \mathrm{~Hz}, 1 \mathrm{H}, 8^{\prime}-\mathrm{H}\right), 7.95(\mathrm{~s}$, $\left.1 \mathrm{H}, 10^{\prime}-\mathrm{H}\right), 8.07\left(\mathrm{~d},{ }^{3} \mathrm{~J} 7 \mathrm{~Hz}, 1 \mathrm{H}, 1^{\prime}-\mathrm{H}\right), 8.31$ (ddd, $\left.{ }^{3} \mathrm{~J} 7 \mathrm{~Hz},{ }^{3} \mathrm{~J} 7 \mathrm{~Hz},{ }^{4} \mathrm{~J} 2 \mathrm{~Hz}, 1 \mathrm{H}, 2-\mathrm{H}\right), 8.37\left(\mathrm{dd},{ }^{3} \mathrm{~J} 9 \mathrm{~Hz},{ }^{4} \mathrm{~J} 2 \mathrm{~Hz}, 1 \mathrm{H}\right.$, 9-H), $8.39\left(\mathrm{~d},{ }^{3} \mathrm{~J} 9 \mathrm{~Hz}, 1 \mathrm{H}, 5-\mathrm{H}\right), 8.60\left(\mathrm{~d},{ }^{4} \mathrm{~J} 2 \mathrm{~Hz}, 1 \mathrm{H}, 7-\mathrm{H}\right), 8.67-8.73(\mathrm{~m}, 2 \mathrm{H}, 3-\mathrm{H}, 4-\mathrm{H}), 8.75\left(\mathrm{~d},{ }^{3} \mathrm{~J} 9 \mathrm{~Hz}, 1 \mathrm{H}, 6-\right.$ $\mathrm{H}), 8.87\left(\mathrm{~d},{ }^{3} \mathrm{~J} 8 \mathrm{~Hz}, 1 \mathrm{H}, 4^{\prime}-\mathrm{H}\right), 8.95\left(\mathrm{~d},{ }^{3} \mathrm{~J} 8 \mathrm{~Hz}, 1 \mathrm{H}, 5^{\prime}-\mathrm{H}\right), 9.26\left(\mathrm{~d},{ }^{3} \mathrm{~J} 9 \mathrm{~Hz}, 1 \mathrm{H}, 10-\mathrm{H}\right), 10.43\left(\mathrm{~d},{ }^{3} \mathrm{~J} 7 \mathrm{~Hz}, 1 \mathrm{H}, 1-\mathrm{H}\right)$. $-{ }^{13} \mathrm{C}-\mathrm{NMR}\left(150 \mathrm{MHz}, \mathrm{DMSO}-d_{6}\right): \delta=118.4$ (C10), 122.9 (C4'), 123.3 (C5), 123.6 (C5'), 124.5 (C2), 125.7 (C8'), 127.1 (C6a), 127.2 (C6'), 127.3 (C7'), 127.4 (C2'), 127.6 (C3'), 128.5 (C4), 128.5 (C10'), 128.9 (C1'), 129.6 (C8a'), 129.7 (C4a'), 130.2 (C4b'), 130.8 (C10a'), 130.9 (C7), 133.6 (C10a), 134.3 (C9), 134.6 (C1), 135.4 (C9'), 136.5 (C6), 140.6 (C3), 141.9 (C8), 143.2 (C4a). - MS (ESI $\left.\left.{ }^{+}\right): m / z=356(100)\left[\mathrm{M}-\mathrm{BF}_{4}\right]^{+} .-\mathrm{MS}(\mathrm{ESI})^{-}\right): m / z=973(100)$ $\left[2 \mathrm{M}+\mathrm{BF}_{4}\right]^{-}$. Anal. for $\mathrm{C}_{27} \mathrm{H}_{18} \mathrm{BF}_{4} \mathrm{~N} \cdot 1 / 2 \mathrm{H}_{2} \mathrm{O}$ (452.26), calcd (\%): C 71.71, H 4.23, N 3.10, found: C 71.60, H 3.88, N 3.16 . 
9-(Phenanthren-9-yl)benzo[b]quinolizinium bromide (8). Under a nitrogen-gas atmosphere, a solution of benzo[b]quinolizinium-9-boronic acid $(6,650 \mathrm{mg}, 2.14 \mathrm{mmol}), 9$-bromophenanthrene $(7,500 \mathrm{mg}, 1.94 \mathrm{mmol})$, $\mathrm{KF}(450 \mathrm{mg}, 7.76 \mathrm{mmol})$, and $\mathrm{Pd}(\mathrm{dppf}) \mathrm{Cl}_{2}-\mathrm{CH}_{2} \mathrm{Cl}_{2}(47.1 \mathrm{mg}, 63.0 \mu \mathrm{mol})$ in $\mathrm{DME} / \mathrm{MeOH} / \mathrm{H}_{2} \mathrm{O}(2 / 1 / 1,24 \mathrm{~mL}) \mathrm{was}$ stirred for $24 \mathrm{~h}$ at $80^{\circ} \mathrm{C}$. After cooling to $\mathrm{rt}$, the reaction mixture was filtered from insoluble components. The solvents were removed under reduced pressure, and the residue was recrystallized from $\mathrm{MeOH}$ to give the product 8 as a yellow microcrystalline solid $(112 \mathrm{mg}, 312 \mu \mathrm{mol}, 16 \%) ; \mathrm{mp} 278-280{ }^{\circ} \mathrm{C}$ (dec.). $-{ }^{1} \mathrm{H}-\mathrm{NMR}$ $\left(600 \mathrm{MHz}, \mathrm{DMSO}-d_{6}\right): \delta=7.67\left(\mathrm{dd},{ }^{3} \mathrm{~J} 7 \mathrm{~Hz},{ }^{3} \mathrm{~J} 7 \mathrm{~Hz}, 1 \mathrm{H}, 7^{\prime}-\mathrm{H}\right), 7.73\left(\mathrm{dd},{ }^{3} \mathrm{~J} 7 \mathrm{~Hz},{ }^{3} \mathrm{~J} 7 \mathrm{~Hz}, 1 \mathrm{H}, 2^{\prime}-\mathrm{H}\right), 7.78-7.83(\mathrm{~m}$, $\left.3 \mathrm{H}, 3^{\prime}-\mathrm{H}, 6^{\prime}-\mathrm{H}, 8^{\prime}-\mathrm{H}\right), 7.99\left(\mathrm{dd},{ }^{3} \mathrm{~J} 7 \mathrm{~Hz},{ }^{3} \mathrm{~J} 7 \mathrm{~Hz}, 1 \mathrm{H}, 3-\mathrm{H}\right), 8.03\left(\mathrm{~s}, 1 \mathrm{H}, 10^{\prime}-\mathrm{H}\right), 8.08-8.11\left(\mathrm{~m}, 2 \mathrm{H}, 2-\mathrm{H}, 1^{\prime}-\mathrm{H}\right), 8.18$ (d, $\left.{ }^{3} \mathrm{~J} 9 \mathrm{~Hz}, 1 \mathrm{H}, 8-\mathrm{H}\right), 8.57\left(\mathrm{~d},{ }^{3} \mathrm{~J} 9 \mathrm{~Hz}, 1 \mathrm{H}, 1-\mathrm{H}\right), 8.58-8.62(\mathrm{~m}, 2 \mathrm{H}, 10-\mathrm{H}, 7-\mathrm{H}), 8.91\left(\mathrm{~d},{ }^{3} \mathrm{~J} 8 \mathrm{~Hz}, 1 \mathrm{H}, 4^{\prime}-\mathrm{H}\right), 8.99$ (d, $\left.{ }^{3} \mathrm{~J} 8 \mathrm{~Hz}, 1 \mathrm{H}, 5^{\prime}-\mathrm{H}\right), 9.27$ (s, $\left.1 \mathrm{H}, 11-\mathrm{H}\right), 9.34$ (d, $\left.{ }^{3} \mathrm{~J} 7 \mathrm{~Hz}, 1 \mathrm{H}, 4-\mathrm{H}\right), 10.54$ (s, $\left.1 \mathrm{H}, 6-\mathrm{H}\right) .{ }^{13} \mathrm{C}-\mathrm{NMR}(150 \mathrm{MHz}$, DMSO- $d_{6}$ ): $\delta=122.4$ (C3), 123.0 (C4'), 123.8 (C5'), 124.7 (C11), 125.2 (C6a), 125.8 (C8'), 126.9 (C1), 127.2 (C10), 127.4 (C6'), 127.5 (C7'), 127.5 (C2'), 127.9 (C3'), 128.2 (C7), 128.8 (C10'), 129.1 (C1'), 129.4 (C8a'), 129.9 (C4a'), 130.3 (C4b'), 130.8 (C10a'), 131.3 (C2), 133.4 (C8), 134.4 (C4), 135.6 (C10a), 136.1 (C9'), 137.8 (C11a), 140.1 (C6), 146.1 (C9). MS (ESI $\left.{ }^{+}\right): m / z=356(100)[\mathrm{M}-\mathrm{Br}]^{+}$. Anal. for $\mathrm{C}_{27} \mathrm{H}_{18} \mathrm{BrN} \cdot 2 \mathrm{H}_{2} \mathrm{O}$ (472.38), calcd (\%): C 68.65, H 4.69, N 2.97, found: C 68.85, H 4.37, N 3.10.

\section{Acknowledgements}

We thank Ms. Sarah Kölsch and Ms. Sandra Uebach for technical assistance and Dr. Mohamed Mahmoud and Mr. Christoph Dohmen for the photographic documentation. PMP thanks the Fond der Chemischen Industrie for a PhD fellowship. Financial support by the Deutsche Forschungsgemeinschaft and the University of Siegen is gratefully acknowledged.

\section{Supplementary Material}

Supplementary material (SI) available: Emission colors of compound $8 ;{ }^{1} \mathrm{H}$ and ${ }^{13} \mathrm{C}$ NMR spectra of compounds $\mathbf{3 b}, \mathbf{3 c}, \mathbf{5}$, and $\mathbf{8}$ can be found in the online version of the text.

\section{References}

1. Schramm, S.; Weiss, D. Adv. Heterocycl. Chem. 2019, 128, 103.

https://doi.org/10.1016/bs.aihch.2018.10.003

2. Machado, G. V.; Stock, R. I.; Reichardt, C. Chem. Rev. 2014, 114, 10429.

https://doi.org/10.1021/cr5001157

3. Bosson, J.; Gouin, J.; Lacour, J. Chem. Soc. Rev. 2014, 43, 2824.

https://doi.org/10.1039/c3cs60461f

4. Christie, R. Color Chemistry, RSC Publishing: Cambridge, 2014.

5. Deligeorgiev, T.; Vasilev, A.; Kaloyanovaa, S.; Vaquero, J. J. Color. Technol. 2010, 126, 55. https://doi.org/10.1111/j.1478-4408.2010.00235.x

6. Zollinger, H. Color Chemistry, Wiley-VCH: Weinheim, 2003.

7. Kozma, E.; Kele, P. Org. Biomol. Chem. 2019, 17, 215. 
https://doi.org/10.1039/C8OB02711K

8. Dsouza, R. N.; Pischel, U.; Nau, W. N. Chem. Rev. 2011, 111, 7941.

https://doi.org/10.1021/cr200213s

9. Klymchenko, A. S. Acc. Chem. Res. 2017, 50, 366.

https://doi.org/10.1021/acs.accounts.6b00517

10. Granzhan, A.; Ihmels, H.; Tian, M. Arkivoc 2015, vi, 494.

https://doi.org/10.3998/ark.5550190.p009.339

11. Das, A. K.; Ihmels, H.; Kölsch, S. Photochem. Photobiol. Sci. 2019, 18, 1373. https://doi.org/10.1039/C9PP00096H

12. Das, A. K. S.; Druzhinin, S.; Ihmels, H.; Müller, M.; Schönherr, H. Chem. Eur. J. 2019, 25, 12703. https://doi.org/10.1002/chem.201903017

13. Bosch, P.; Sucunza, D.; Mendicuti, A.; Domingo, A.; Vaquero, J. J. Org. Chem. Front. 2018, 5, 1916. https://doi.org/10.1039/C8Q000236C

14. Kadam, V. D.; Feng, B.; Chen, X.; Liang, W.; Zhou, F.; Liu, Y.; Gao, G.; You, J. Org. Lett. 2018, $20,7071$. https://doi.org/10.1021/acs.orglett.8b03015

15. Zacharioudakis, E.; Cañeque, T.; Custodio, R.; Müller, S.; Cuadro, A. M.; Vaquero, J. J.; Rodriguez, R. Bioorg. Med. Chem. Lett. 2017, 27, 203.

https://doi.org/10.1016/j.bmcl.2016.11.074

16. Yue, X.; Armijo, Z.; King, K.; Bondar, M. V.; Morales, A. R.; Frazer, A.; Mikhailov, I. A.; Przhonska, O. V.; Belfield, K. D. ACS Appl. Mater. Interfaces 2015, 7, 2833.

https://doi.org/10.1021/am508093p

17. Bortolozzi, R.; von Gradowski, S.; Ihmels, H.; Schäfer, K.; Viola, G. Chem. Commun. 2014, 50, 8242. https://doi.org/10.1039/C4CC02283A

18. Schäfer, K.; Ihmels, H. J. Fluoresc. 2017, 27, 1221.

https://doi.org/10.1007/s10895-017-2107-1

19. Bortolozzi, R.; Ihmels, H.; Thomas, L.; Tian, M.; Viola, G. Chem. Eur. J. 2013, 19, 8736. https://doi.org/10.1002/chem.201301164

20. Pithan, P. M.; Decker, D.; Sardo, M. S.; Viola, G.; Ihmels, H. Beilstein J. Org. Chem. 2016, $12,854$. https://doi.org/10.3762/bjoc. 12.84

21. Tian, M.; Ihmels, H.; Ye, S. Org. Biomol. Chem. 2012, 10, 3010. https://doi.org/10.1039/c2ob06948b

22. Bandaru, S. S. M.; Dzubiel, D.; Ihmels, H.; Karbasiyoun, M.; Mahmoud, M. M. A.; Schulzke, C. Beilstein J. Org. Chem. 2018, 14, 1871.

https://doi.org/10.3762/bjoc. 14.161

23. Cañeque, T.; Cuadro, A. M., Alvarez-Builla, J.; Pérez-Moreno, J.; Clays, K.; Castaño, O.; Andrés, J. L.; Vaquero, J. J. Dyes Pigments 2014, 101, 116.

https://doi.org/10.1016/j.dyepig.2013.09.031

24. Cañeque, T.; Cuadro, A. M.; Custodio, Alvarez-Builla, J.; Batanero, B.; Gómez-Sal, P.; Javier Pérez-Moreno, J.; Koen Clays, J.; Castaño, O.; Andrés, J. L.; Carmona, T.; Mendicuti, F.; Juan J. Vaquero, J. J. Dyes Pigments 2017, 144, 17.

https://doi.org/10.1016/j.dyepig.2017.05.005

25. Tian, M.; Ihmels, H. Synthesis 2009, 24, 4226.

https://doi.org/10.1055/s-0029-1217060

26. Liu, Y.; Lu, Y.; Prashad, M.; Repi, O.; Blacklock, T. J. Adv. Synth. Catal. 2005, 347, 217. 
https://doi.org/10.1002/adsc.200404236

27. Benner, K.; Ihmels, H.; Kölsch, S.; Pithan, P. M. Org. Biomol. Chem. 2014, 12, 1725. https://doi.org/10.1039/C3OB42140F

28. Fozard, A.; Bradsher, C. K. J. Org. Chem. 1966, 31, 2346. https://doi.org/10.1021/j001345a063

29. Leermann, T.; Leroux, F. R.; Colobert, F. Org. Lett. 2011, 13, 4479. https://doi.org/10.1021/ol2016252

30. Jones, G.; Jackson, W. R.; Choi, C. Y.; Bergmark, W. R. J. Phys. Chem. 1985, 89, 294. https://doi.org/10.1021/j100248a024

31. Crosby, G. A.; Demas, J. N. J. Phys. Chem. 1971, 75, 991. https://doi.org/10.1021/j100678a001

32. Valeur, B.; Berberan-Santos, M. N. Molecular Fluorescence. Principles and Applications, Wiley-VCH, Weinheim, 2012.

https://doi.org/10.1002/9783527650002

This paper is an open access article distributed under the terms of the Creative Commons Attribution (CC BY) license (http://creativecommons.org/licenses/by/4.0/) 